DOI: https://doi.org/10.24127/ajpm.v10i1.3226

\title{
PENGEMBANGAN HANDOUT BERBASIS GUIDED NOTE TAKING PADA MATERI SISTEM PERSAMAAN LINEAR TIGA VARIABEL
}

\author{
Neti Diana $^{1^{*}}$, Sugeng Sutiarso ${ }^{2}$, Haninda Bharata $^{3}$ \\ $1^{*}, 2,3$ Pendidikan Matematika, Universitas Lampung \\ *Corresponding author. \\ E-mail: netidiana11@gmail.com ${ }^{\left.{ }^{*}\right)}$ \\ sugengsutiarso7@gmail.com ${ }^{2)}$

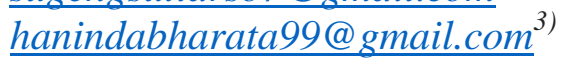

Received 09 November 2020; Received in revised form 12 March 2021; Accepted 29 March 2021

\begin{abstract}
Abstrak
Penelitian ini bertujuan untuk mengembangkan bahan ajar berupa handout berbasis guided note taking pada materi sistem persamaan linear tiga variabel dan mengetahui kualitas handout dilihat dari aspek kevalidan dan kepraktisan. Penelitian ini merupakan penelitian pengembangan yang mengacu pada model pengembangan 4D, yaitu define, design, develop, disseminate. Subjek dalam penelitian ini adalah 2 guru dan 5 siswa SMAN 1 Buay Bahuga. Instrumen yang digunakan untuk mengukur kualitas handout yang dikembangkan meliputi angket ahli, angket respon guru dan siswa. Angket ahli digunakan untuk mengukur kevalidan handout sedangkan angket respon guru dan siswa digunakan untuk mengukur kepraktisan handout. Produk penelitian berupa handout berbasis guided note taking pada materi sistem persamaan linear tiga variabel kelas X SMA. Hasil penelitian menunjukkan bahwa dilihat dari aspek kevalidan termasuk dalam kategori valid dengan skor rata-rata 75 berdasarkan penilaian dua dosen ahli (ahli materi, desain dan bahasa); dilihat dari respon dua guru dengan rata-rata 42,5 termasuk dalam kategori baik dan respon siswa dengan rata-rata 41,8 ternasuk dalam kategori baik sehingga aspek kepraktisan dikategorikan praktis berdasarkan hasil respon pengguna handout. Berdasarkan hasil penelitian dapat disimpulkan bahwa handout berbasis guided note taking pada materi sistem persamaan linear tiga variabel yang dikembangkan adalah valid dan praktis digunakan dalam pembelajaran.
\end{abstract}

Kata kunci: guided note taking; handout; $R \& D$.

\begin{abstract}
This study aims to develop teaching materials in the form of handouts based on Guided Note Taking on the system material of three-variable linear equations and to determine the quality of handouts in terms of validity and practicality. This research is a development research that refers to the $4 D$ development model namely define, design, develop, disseminate. The subjects in this study were 2 teachers and 5 students of SMAN 1 Buay Bahuga. The instruments used to measure the quality of the handouts developed included expert questionnaires, teacher and student response questionnaires. Expert questionnaires were used to measure the validity of the handouts, while teacher and student response questionnaires were used to measure the practicality of the handouts. The research product was a handout based on Guided Note Taking on the material of the system of linear equations of three variables for class X SMA. The results showed that from the aspect of validity it was included in the valid category with an average score of 75 based on the assessment of two expert lecturers (material, design and language experts); of the two teachers' responses with an average of 42.5 were in the good category and the student responses with an average of 41.8 were in the good category so that the practicality aspect was categorized as practical based on the results of the handout user's response. Based on the research results, it can be concluded that the handout based on guidance notes on the material for the three-variable linear equation system developed is valid and can be used practically in learning.
\end{abstract}

Keywords: guided note taking; handout; $R \& D$.

This is an open access article under the Creative Commons Attribution 4.0 International License 


\section{PENDAHULUAN}

Pendidikan bukan hanya sebagai sarana penyampai ilmu, namun pendidikan merupakan suatu proses pembentukan tingkah laku yang diinginkan oleh lingkungan (Khoiriyah \& Rizki, 2017). Dalam meningkatkan kualitas pendidikan, guru dan siswa merupakan unsur sangat penting untuk mencapai suatu keberhasilan pendidikan. Interaksi yang terjalin dengan baik antara guru dan siswa dalam proses pembelajaran akan meningkatkan kualitas pendidikan. Proses pembelajaran merupakan proses komunikasi dan berlangsung dalam suatu sistem. Ada dua unsur yang saling terikat dalam proses pembelajaran yaitu metode mengajar dan media pembelajaran. Sebagai fasilitator, guru dapat mengembangkan berbagai cara untuk memudahkan siswa dalam proses pembelajaran (Agitsa, Wahyuni \& Friansah, 2019). Pembelajaran yang melibatkan siswa secara aktif akan lebih efektif apabila guru mampu mengembangkan bahan ajar sesuai dengan karakteristik materi pelajaran. Pengembangan bahan ajar adalah proses pemilihan, adaptasi, dan pembuatan bahan ajar berdasarkan kerangka acuan tertentu serta didasarkan pada analisis kebutuhan (Rahmawati \& Vahlia, 2017). Bahan ajar yang digunakan di kelas dan sesuai dengan tuntutan kurikulum yang berlaku, maka siswa akan lebih kritis dalam memecahkan masalah matematika (Agitsa, Wahyuni \& Friansah, 2019).

Berdasarkan hasil observasi pembelajaran yang dilakukan di SMA N 1 Buay Bahuga didapatkan bahwa dalam proses pembelajaran belum menggunakan bahan ajar bantu selain buku paket. Pemakaian buku cetakan penerbit hanya memungkinkan komunikasi satu arah yang berakibat pada kurangnya kesempatan siswa untuk mengembangkan pola pikir dan pembentukan konsep sehingga siswa kesulitan untuk memahami materi yang diajarkan Ketersediaan bahan ajar lain seperti handout juga belum ada. Keterbatasan tersebut, tentunya akan berpengaruh pada kualitas pembelajaran, sehingga siswa kesulitan dalam memahami materi pelajaran. Handout sebagai bahan pembelajaran dapat dikembangkan berdasarkan kebutuhan (Wulandari, Suarsini \& Ibrohim, 2016). Sehingga bahan ajar yang dapat dikembangkan adalah handout.

Hasil wawancara dengan siswa didapatkan bahwa perhatian guru dalam proses pembelajaran dirasakan siswa kurang menyeluruh. Siswa masih kesulitan dalam memahami materimateri kontekstual. Untuk mengatasi hal tersebut diperlukan pengembangan handout selain buku cetakan penerbit. Guru juga harus memilih metode yang terbaik agar proses pembelajaran berlangsung dengan efektif. Salah satu metode pembelajaran yang mampu membimbing dan mengoptimalkan hasil belajar siswa dan dapat diterapkan dalam handout yaitu metode pembelajaran Guided Note Taking. Metode Guided Note Taking atau catatan terbimbing adalah metode pembelajaran yang digunakan guru dengan menyiapkan suatu bagan atau peta konsep dengan beberapa point penting dihilangkan sebagai media yang dapat membantu siswa dalam membuat catatan ketika guru sedang menyampaikan pelajaran di kelas. Metode pembelajaran Guided Note Taking ini bertujuan agar pelaksanaan pembelajaran dalam kelas mendapat perhatian siswa, terutama pada kelas dengan jumlah siswa yang cukup banyak (Roziqiyah \& Wiyatmo, 2017). 
Penelitian tentang pengembangan handout berbasis guided note taking pada materi koloid (Ulya, Sari \& Ismayani, 2016), akan tetapi penelitian ini dilakukan pada mata pelajaran kimia. Beberapa penelitian lain yang menyatakan bahwa handout valid, praktis dan efektif digunakan dalam proses pembelajaran seperti yang dikaji Uyun, Holisin \& Kristanti (2017); Sari, Jasmidi, Kembaren \& Sudrajat (2018); Aini \& Masykur (2018). Penelitianpenelitian tersebut belum ada yang mengembangkan handout berbasis guided note taking pada materi matematika khususnya pada materi sistem persamaan linear tiga variabel.

Handout dengan catatan terbimbing memiliki dampak positif pada pembelajaran karena siswa lebih fokus dan lebih baik dalam memproses informasi utama. Handout berbasis metode ini siswa dibimbing dalam menyelesaikan suatu permasalahan (Chen, Theo \& Zhou, 2017). Handout yang disiapkan guru digunakan untuk mendukung siswa selama pembuatan catatan dengan mengurangi tuntutan kognitif yang diperlukan maka siswa dapat berhasil menyelesaikan tugastugas dengan baik (Haydon, Mancil, Kroeger, McLeskey \& Lin, 2011). Oleh karena itu, penelitian ini bertujuan untuk mengembangkan bahan ajar berupa handout berbasis guided note taking pada materi sistem persamaan linear tiga variabel dan mengetahui kualitas handout dilihat dari aspek kevalidan dan kepraktisan.

\section{METODE PENELITIAN}

Penelitian ini merupakan penelitian dan pengembangan yang bertujuan untuk menghasilkan produk berupa handout berbasis guided note taking pada materi sistem persamaan linear tiga variabel di SMA Negeri 1
Buay Bahuga. Penelitian ini menggunakan model 4-D yang meliputi pendefinisian (Define), perancangan (Design), pengembangan (Develop), penyebaran (Disseminate).

Tahap Pendefinisian (Define): Tahapan ini mendefinisikan syaratsyarat pembelajaran yaitu analisis tujuan dalam batasan materi pelajaran yang dikembangkan perangkatnya, terdiri dari langkah pokok yaitu analisis awal akhir, analisis siswa, analisis konsep, analisis tugas, perumusan tujuan pembelajaran dan penyusunan perangkat penelitian.

Tahap Perancangan (Design): tahap perancangan bertujuan merancang produk handout berbasis guided note taking. Kemudian disusun beberapa draf penilaian aspek kevalidan dan aspek kepraktisan handout.

Tahap Pengembangan (Develop): tujuan tahap ini adalah menghasilkan produk pengembangan yang sudah direvisi berdasarkan masukan dari para pakar, kemudian diuji coba kelompok kecil. Validasi handout berbasis guided note taking meliputi validasi isi, validasi desain dan validasi keterbacaan/bahasa. Validasi dilakukan dengan 2 ahli yang merupakan dosen Pendidikan Matematika Universitas Lampung. Uji coba kelompok kecil dilakukan dengan memberikan produk kepada 2 guru mata pelajaran matematika dan 5 siswa SMA Negeri 1 Buay Bahuga yang sudah menempuh materi sistem persamaan linear tiga variabel.

Tahap Penyebaran (Disseminate): pada konteks pengembangan handout ini tahap disseminate dilakukan penyebaran terbatas dengan cara memberikan handout dalam bentuk softfile kepada guru matematika di SMAN 1 Buay Bahuga, namun handout tidak diproduksi secara masal karena keterbatasan. 
DOI: https://doi.org/10.24127/ajpm.v10i1.3226

Teknik pengumpulan data penelitian ini adalah angket. Angket ini digunakan untuk mengetahui kevalidan dan kepraktisan produk yang dikembangkan. Analisis kevalidan handout, kepraktisan dianalisis secara kuantitatif dengan menghitung rata-rata skor (1).

$$
\bar{X}=\frac{\sum X}{n}
$$

Keterangan:

$$
\begin{array}{ll}
\bar{X} & =\text { skor rata-rata } \\
\sum X & =\text { jumlah skor } \\
n & =\text { jumlah penilai }
\end{array}
$$

Menurut Mardapi (2015) hasil penilaian kelayakan dikonversi menjadi kualitatif untuk menentukan kualitas handout yang dibuat. Kriteria penilaian kevalidan dan kepraktisan handout masing-masing dijabarkan pada Tabel 1 dan Tabel 2.

Tabel 1. Kriteria penilaian kevalidan produk

\begin{tabular}{ccc}
\hline No. & Rentang Skor Kuantitatif & Kategori Kualitatif \\
\hline 1 & $\bar{X} \geq 75$ & Sangat Baik \\
2 & $75>\bar{X} \geq 62,5$ & Baik \\
3 & $62,5>\bar{X} \geq 50$ & Kurang Baik \\
4 & $\bar{X}<50$ & Sangat Kurang Baik \\
\hline
\end{tabular}

Tabel 2. Kriteria penilaian kepraktisan produk

\begin{tabular}{ccc}
\hline No. & Rentang Skor Kuantitatif & Kategori Kualitatif \\
\hline 1 & $\bar{X} \geq 36$ & Sangat Baik \\
2 & $36>\bar{X} \geq 30$ & Baik \\
3 & $30>\bar{X} \geq 24$ & Kurang Baik \\
4 & $\bar{X}<24$ & Sangat Kurang Baik \\
\hline
\end{tabular}

\section{HASIL DAN PEMBAHASAN}

Tahap Pendefinisian, tahap ini dilakukan untuk menetapkan dan mendefinisikan syarat-syarat pengembangan. Perolehan informasi dari tahap ini dilakukan dengan cara observasi langsung dan wawancara kepada guru dan siswa di SMA Negeri 1 Buay Bahuga. Guru menyarankan materi yang digunakan dalam penelitian adalah sistem persamaan linear tiga variabel karena dalam pembelajaran siswa masih kesulitan dalam materimateri kontekstual, dan cenderung belum memahami dalam memodelkan matematika dengan sederhana. Setelah materi yang dikembangkan sudah ditentukan langkah selanjutnya adalah studi pustaka untuk mengumpulkan materi tambahan SPLTV. Dalam tahap ini juga dilakukan perumusan indikator tujuan pembelajaran yang diharapkan tercapai dalam pembelajaran. Ketersediaan bahan ajar selain buku dari penerbit diharapkan proses pembelajaran menjadi lebih efektif terutama pada siswa yang jumlahnya cukup banyak. Oleh karena itu, handout adalah alternatif bahan ajar tambahan yang dikembangkan dalam penelitian ini.

Tahap Perancangan, tahap ini dilakukan penyusunan rancangan awal handout berbasis guided note taking dengan materi sistem persamaan linear tiga variabel. Produk yang dihasilkan berupa bahan ajar cetak untuk guru dan 
untuk siswa dengan menggunakan kertas A4. Pembuatan cover handout dan isi handout menggunakan software Microsoft Word 2016. Rancangan awal cover handout dapat dilihat pada Gambar 1.

Selanjutnya rancangan isi handout berbasis guided note taking materi SPLTV menggunakan latar belakang putih, dengan diberikan beberapa animasi gambar dan warna. Secara umum jenis tulisan pada isi handout ini menggunakan jenis Times New Roman. Handout terdiri dari cover, pendahuluan, isi handout yaitu materi singkat dan contoh soal yang harus dilengkapi siswa serta latihan soal yang dapat dikerjakan secara berkelompok. Desain isi handout dapat dilihat pada Gambar 2 dan Gambar 3. Adapun instrumen yang disusun yaitu angket validasi materi, desain, dan bahasa serta angket respon yang diberikan kepada guru dan siswa selaku pengguna handout.

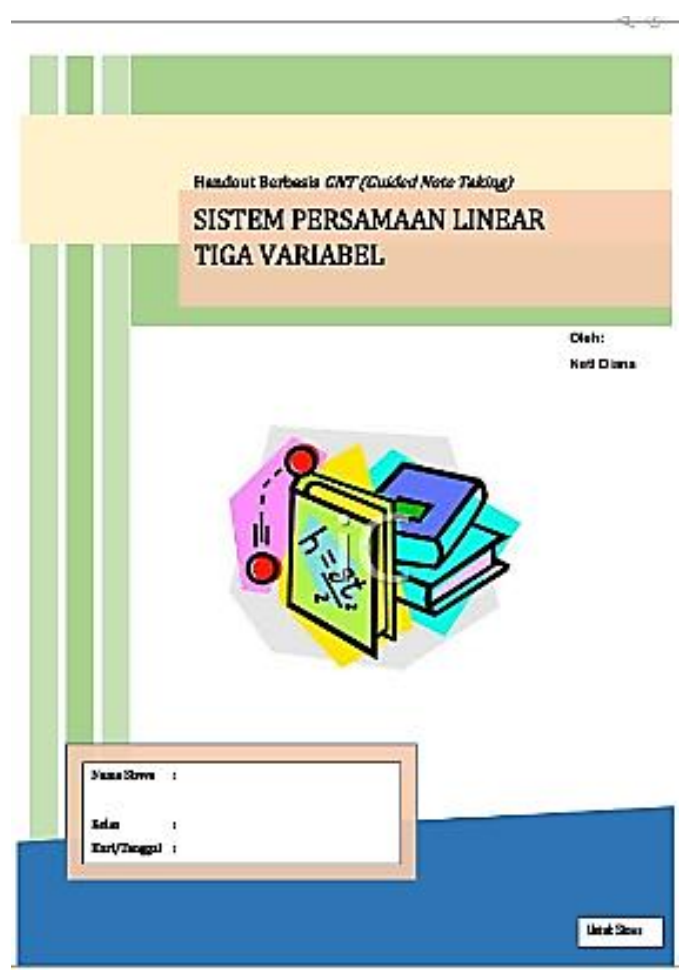

Gambar 1. Cover handout

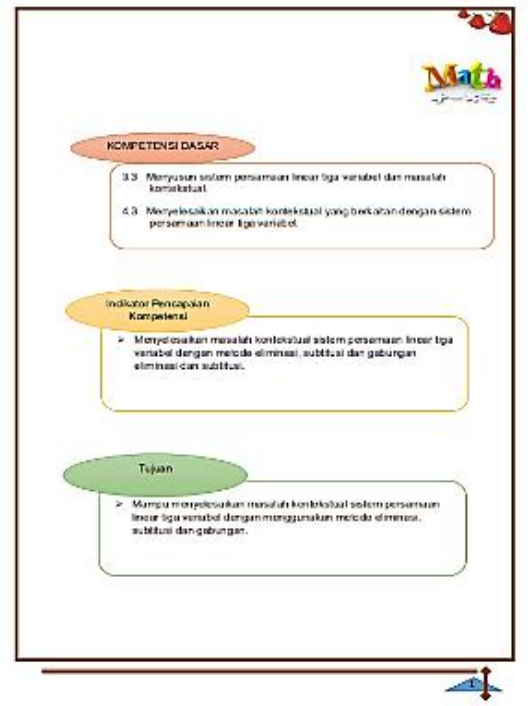

Gambar 2. Pendahuluan handout

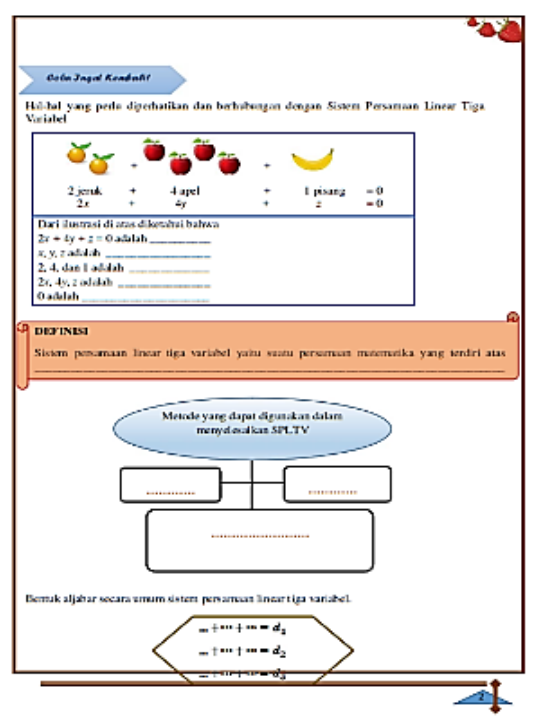

Gambar 3. Contoh isi handout

Tahap Pengembangan, Pada tahap pengembangan ini dilakukan uji validasi handout yang telah dibuat dan dilakukan uji coba terbatas.

\section{Uji Validasi}

Penilaian yang diberikan oleh para ahli berdasarkan skala jawaban yang ada pada lembar angket validasi yang sesuai dengan pendapat dan pengalaman keahlian masing-masing validator. Hasil penilaian kedua validator ini yang kemudian dianalisis 
DOI: https://doi.org/10.24127/ajpm.v10i1.3226

dan digunakan untuk melihat tingkat kelayakan handout berbasis guided note taking. Validasi dilakukan kepada dua dosen Pendidikan Matematika
Universitas Lampung. Adapun ringkasan penilaian validator disajikan pada Tabel 3.

Tabel 3. Hasil analisis kelayakan handout berbasis guided note taking

\begin{tabular}{llccc}
\hline \multirow{2}{*}{ No. } & \multicolumn{1}{c}{ Aspek } & \multicolumn{2}{c}{ Jumlah Skor Validator ke- } & \multirow{2}{*}{ Rata-Rata } \\
\cline { 2 - 4 } & & $\mathbf{1}$ & $\mathbf{2}$ & \\
\hline 1. & Isi/Materi & 39 & 34 & 36,5 \\
2. & Tampilan/Desain & 23 & 19 & 21 \\
3. & Bahasa/Keterbacaan & 20 & 15 & 17,5 \\
& Jumlah & 82 & 68 & \\
& Rata-Rata & & & 75 \\
& Kategori & & & Sangat Baik \\
\hline
\end{tabular}

Tabel 3 menunjukkan rata-rata penilaian validator pada seluruh aspek adalah 75. Sesuai dengan kriteria penilaian pada Tabel 1 termasuk dalam interval $\bar{X} \geq 75$ dengan kategori sangat baik. Berdasarkan hasil analisis uji validasi tersebut dapat disimpulkan bahwa handout berbasis guided note taking yang dikembangkan ini valid dan dikatakan layak digunakan dalam pembelajaran. Selain memberikan penilaian, validasi juga bertujuan untuk memperbaiki handout dengan menggunakan saran dan komentar dari validator. Beberapa komentar dan saran dari ahli disajikan dalam Tabel 4.

Tabel 4. Komentar dan saran validator

\begin{tabular}{lll} 
No. & \multicolumn{1}{c}{ Aspek } & \multicolumn{1}{c}{ Komentar dan Saran } \\
\hline 1. $\quad$ Isi/Materi & 1) $\begin{array}{l}\text { Kalimat perintah belum jelas sehingga ilustrasi yang } \\
\text { dibuat belum mengarah pada komunikasi matematis } \\
\text { dan penerimaan konsep. }\end{array}$ \\
& 2) $\begin{array}{l}\text { Pengisian model matematika sebaiknya dihilangkan } \\
\text { agar siswa bebas berekspresi. }\end{array}$ \\
2. Tampilan/Desain & 1) $\begin{array}{l}\text { Tambahkan keterangan gambar atau ilustrasi } \\
\text { Tabel kesimpulan dari pernyataan berada diakhir } \\
\text { atau dibawah }\end{array}$ \\
3. & 2) & 1) $\begin{array}{l}\text { Penggunaan simbol matematika yang belum } \\
\text { konsisten. }\end{array}$ \\
& 2) \begin{tabular}{l} 
Petunjuk pengisian bagan masih kurang jelas \\
\hline
\end{tabular}
\end{tabular}

\section{Uji Coba Terbatas}

Uji coba terbatas dilakukan untuk mengetahui respon pengguna handout. Angket respon yang diberikan kepada guru dan siswa berisi 12 pernyataan tentang tanggapan mengenai handout berbasis guided note taking. Data respon pengguna handout diperoleh dari uji coba kelompok kecil disajikan pada Tabel 5 dan Tabel 6. 
DOI: https://doi.org/10.24127/ajpm.v10i1.3226

Tabel 5. Hasil respon guru terhadap handout berbasis guided note taking

\begin{tabular}{clccc}
\hline \multirow{2}{*}{ No. } & \multicolumn{1}{c}{ Aspek } & \multicolumn{2}{c}{ Jumlah Skor Responden ke- } & \multirow{2}{*}{ Rata-Rata } \\
\cline { 2 - 4 } & & $\mathbf{1}$ & $\mathbf{2}$ & \\
\hline 1. & Kemenarikan & 11 & 10 & 10,5 \\
2. & Kebermanfaatan & 22 & 22 & 22 \\
3. & Keterbacaan & 10 & 10 & 10 \\
& Jumlah & 43 & 42 & 42,5 \\
& Rata-Rata & & & Sangat Baik \\
& Kategori & & & \\
\hline
\end{tabular}

Tabel 5 menunjukkan kualitas kelayakan handout berbasis guided note taking yang dilihat dari respon guru. Penilaian dilakukan oleh 2 guru yaitu Ibu Indrayati, S.Pd dan Bapak Sidik Surojo, S.Pd. Sebelum dilakukan penilaian oleh guru, terlebih dahulu guru diberikan penjelasan terkait handout yang telah dikembangkan. Berdasarkan hasil dari penilaian yang diberikan oleh guru, dapat disimpulkan bahwa handout berbasis guided note taking yang dikembangkan ini praktis karena memiliki respon yang sangat baik. Selanjutnya, untuk hasil respon siswa dapat dilihat pada Tabel 6.

Tabel 6. Hasil respon siswa terhadap handout berbasis guided note taking

\begin{tabular}{|c|c|c|c|c|c|c|c|}
\hline \multirow{2}{*}{ No. } & \multirow{2}{*}{ Aspek } & \multicolumn{5}{|c|}{ Jumlah Skor Responden ke- } & \multirow{2}{*}{ Rata-Rata } \\
\hline & & 1 & 2 & 3 & 4 & 5 & \\
\hline 1. & Kemenarikan & 11 & 10 & 10 & 10 & 9 & 10 \\
\hline 2. & Kebermanfaatan & 21 & 22 & 19 & 22 & 21 & 21 \\
\hline \multirow[t]{4}{*}{3.} & Keterbacaan & 10 & 10 & 12 & 11 & 11 & 10,8 \\
\hline & Jumlah & 42 & 42 & 41 & 43 & 41 & \\
\hline & Rata-Rata & & & & & & 41,8 \\
\hline & Kategori & & & & & & Sangat Baik \\
\hline
\end{tabular}

Tabel 6 menunjukkan kualitas kelayakan handout dilihat dari respon siswa. Penilaian respon ini dilakukan dengan 5 orang siswa tersebut sudah menempuh materi sistem persamaan linear tiga variabel, hal ini terkendala dalam pembelajaran sekolah belum dilakukan tatap muka sehingga untuk mencari siswa sedikit sulit. Siswa diberikan penjelasan singkat mengenai handout kemudian siswa boleh membawa pulang handout yang diberikan dan memberikan penilaian. Berdasarkan respon penilaian siswa tersebut dapat disimpulkan bahwa handout berbasis guided note taking yang dikembangkan ini praktis karena memiliki respon yang sangat baik dan layak digunakan dalam pembelajaran.

Setelah dilakukan uji validasi dan uji coba terbatas, diperoleh hasil handout berbasis guided note taking. Hasil dari bagian pendahuluan dan bagian isi handout berbasis guided note taking dapat dilihat pada Gambar 1 dan Gambar 2. Terlihat pada Gambar 1 bahwa pada bagian pendahuluan handout diberikan penjelasan atau pengertian tentang handout berbasis guided note taking ini. 
DOI: https://doi.org/10.24127/ajpm.v10i1.3226
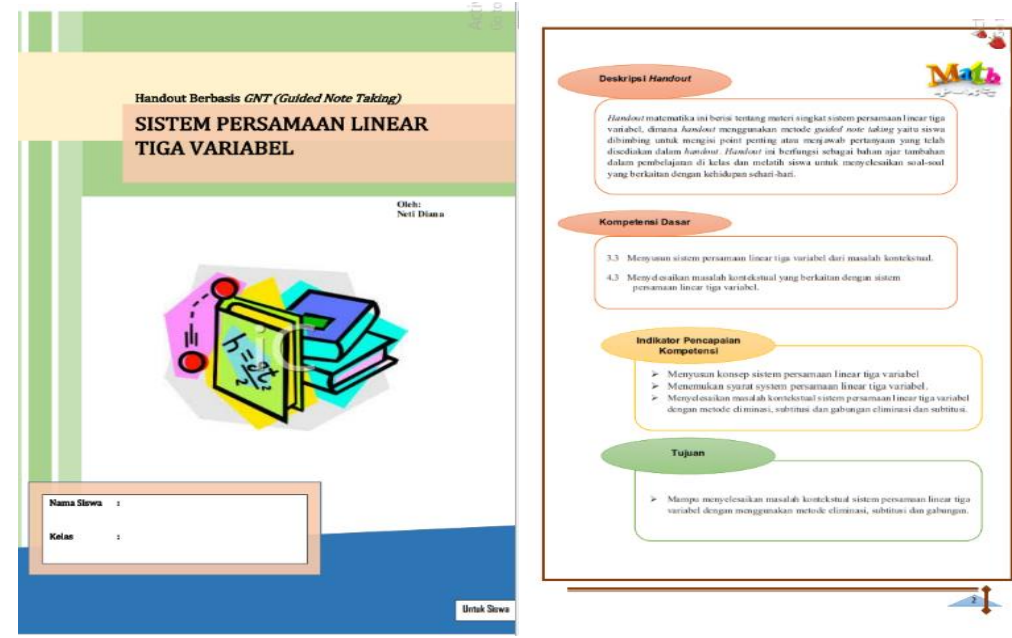

Gambar 1. Cover handout dan pendahuluan handout berbasis guided note taking
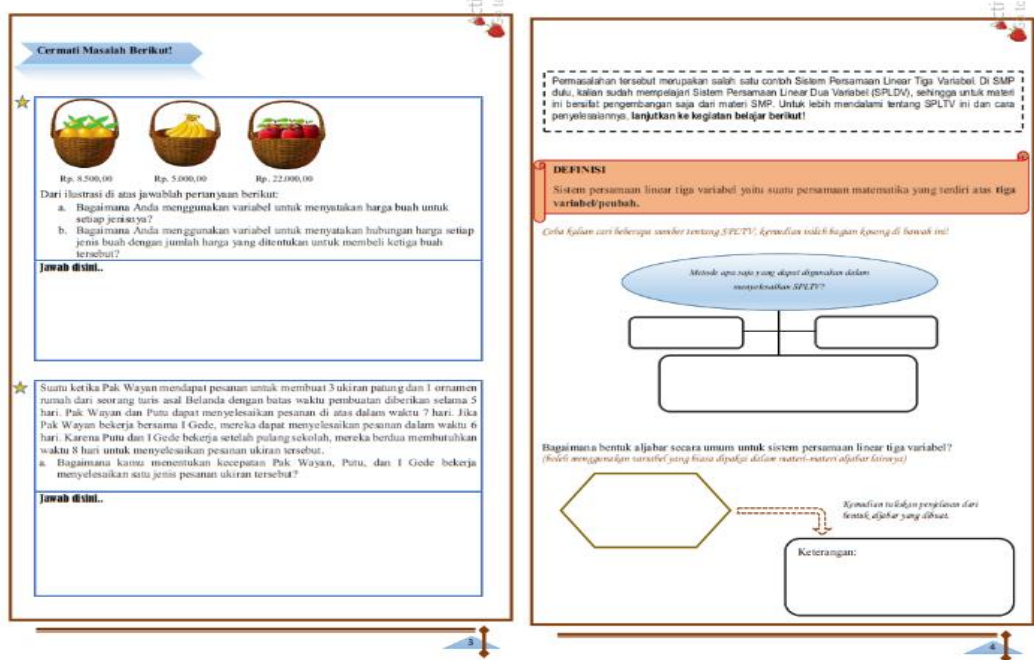

Gambar 2. Isi handout berbasis guided note taking

Gambar 2 menunjukkan bahwa handout yang dikembangkan memuat metode Guided Note Taking yaitu handout yang disiapkan terdapat skema/bagan atau peta konsep dengan beberapa diberikan ruang kosong agar dapat melatih siswa untuk mengasah keterampilan mereka dalam berkomunikasi dan membuat kesimpulan. Siswa lebih memperhatikan guru pada saat pembelajaran berlangsung, karena handout tersebut masih harus dilengkapi siswa yang bersangkutan. Dari fungsi handout tersebut, memberi peluang kepada siswa untuk lebih aktif dalam proses pembelajaran. Desain handout yang dibuat menggunakan aplikasi komputer menghasilkan desain yang sesuai dengan keinginan. Selain itu, handout ini disajikan dengan ilustrasi gambar sehingga siswa tertarik untuk membaca. Hal ini sesuai pada penelitian Ningtyas \& Yunianta (2014) bahwa handout yang baik adalah handout yang dapat digunakan sebagai pedamping bahan ajar, disajikan secara menarik, dan menggunakan bahasa yang mudah dimengerti. 
DOI: https://doi.org/10.24127/ajpm.v10i1.3226

$\begin{array}{ccr}\text { Handout } & \text { ini } & \text { berfungsi } \\ \text { membimbing } & \text { siswa } & \text { dengan }\end{array}$ menggunakan catatan yang ada pada handout. Handout memiliki peta konsep yang disediakan kosong sehingga mendorong siswa mengembangkan kemampuan komunikasinya. Guru juga dapat menunjukkan keterkaitan antara konsep baru dengan konsep yang telah dimiliki siswa sebelumnya. Penelitian yang dilakukan Marissa (2020) bahwa dengan menanamkan konsep-konsep pokok pada peta konsep yang disediakan aktivitas siswa cenderung lebih aktif. Hal ini juga sesuai dengan penelitian Bahri (2020) bahwa dengan mengembangkan peta konsep memberi peluang siswa untuk melatih dan meningkatkan kemampuan komunikasi matematisnya. Namun, produk yang dihasilkan memiliki kekurangan seperti guru harus terlebih dahulu membuat isi handout dan pembuatan handout hanya terbatas pada satu topik materi.

Penelitian ini juga sejalan dengan penelitian terdahulu yaitu Sari \& Putri (2020), Ulya, Sari \& Ismayani (2016), Roziqiyah \& Wiyatmo (2017), dan Sari, Jasmidi, Kembaren \& Sudrajat (2018) dimana penilaian rata-rata kelayakan memperoleh kategori sangat baik. Namun, pembelajaran yang dilakukan belum dilakukan untuk materi pelajaran matematika. Hal ini menunjukkan bahwa produk yang dihasilkan merupakan penerapan untuk mata pelajaran matematika karena dalam pembelajaran matematika belum ada yang menggunakan handout berbasis guded note taking.

Handout berbasis guided note taking diharapkan dapat membantu guru dalam pembelajaran dan guru menjadi lebih kreatif dalam membuat pendamping bahan ajar. Bahan ajar yang digunakan dalam pembelajaran akan menjadi lebih bervariasi. Sumber belajar siswa akan bertambah sehingga proses pembelajaran menjadi lebih efisien. Handout berbasis guided note taking ini juga diharapkan dapat digunakan siswa untuk belajar secara mandiri, karena pada isi handout telah diberikan petunjuk penyelesaian yang berfungsi sebagai pengganti guru. Selain itu juga apabila siswa ingin belajar secara berkelompok maka akan tercipta suasana kegiatan berdiskusi yang baik dan lebih terarah dalam menyelesaikan suatu permasalahan.

\section{KESIMPULAN DAN SARAN}

Berdasarkan hasil penelitian dan pembahasan dapat disimpulkan bahwa handout berbasis guided note taking pada materi sistem persamaan linear tiga variabel yang dikembangkan adalah valid dan praktis digunakan dalam pembelajaran.

Adapun saran untuk penelitian selanjutnya hendaknya menggunakan handout berbasis guided note taking sebagai alternatif sumber belajar tambahan dan melakukan penelitian sampai pada tahap efektifitas produk agar handout yang dikembangkan menjadi lebih baik dan berguna untuk meningkatkan hasil belajar siswa.

\section{DAFTAR PUSTAKA}

Agitsa, L., Wahyuni, R., \& Friansah, D. (2019). Pengembangan Lembar Kerja Siswa Berbasis Problem Based Learning pada Materi Bangun Ruang Sisi Datar. AKSIOMA: Jurnal Program Studi Pendidikan Matematika, 8(3), 429-437.

Aini, E. P., \& Masykur, R. (2018). Handout Matematika berbantuan Etnomatematika Berbasis Budaya Lokal. DESIMAL: Jurnal Matematika, 1(1), 73-79. 
Bahri, S. (2020). Pengembangan Peta Konsep Pada Model Problem Based Learning Untuk Meningkatkan Kemampuan Pemecahan Masalah dan Komunikasi Matematis Siswa. Jurnal MathEducation Nusantara, 3(1), 13-23.

Chen, P. H., Teo, T., \& Zhou, M. (2017).

Effects of Guided Notes on Enhancing College Students' Lecture Note-Taking Quality and Learning Performance. Current Psychology, 36(4), 719-732.

Haydon, T., Mancil, G. R., Kroeger, S. D., McLeskey, J., \& Lin, W.-Y. J. (2011). A Review of the Effectiveness of Guided Notes for Students who Struggle Learning Academic Content. Preventing School Failure: Alternative Education for Children and Youth, 55(4), 226-231.

Khoiriyah, U., \& Rizki, S. (2017). Pengembangan Bahan Ajar Himpunan Matematika Yang Dikaitkan dengan Nilai-Nilai Islam. AKSIOMA: Jurnal Program Studi Pendidikan Matematika, 6(3), 315322.

Mardapi, D. (2015). Pengukuran, Penilaian dan Evaluasi Pendidikan. Yogyakarta: Nuha Liteasi.

Marissa, N. (2020). Penggunaan Metode Peta Konsep Terhadap Hasil Belajar Geografi. Jurnal MERETAS, 7(1), 16-33.

Ningtyas, R., Yunianta, T. N. H., \& Wahyudi, W. (2014). Pengembangan Handout Pembelajaran Tematik untuk Siswa Sekolah Dasar Kelas III. Scholaria: Jurnal Pendidikan Dan Kebudayaan, 4(3), 42-53.

Rahmawati, Y., \& Vahlia, I. (2017). Pengembangan Bahan Ajar Berbasis E Learning pada Matakuliah Evaluasi Pembelajaran untuk
Meningkatkan Hasil Belajar Mahasiswa. AKSIOMA: Jurnal Program Studi Pendidikan Matematika, 6(2), 169-177.

Roziqiyah, S., \& Wiyatmo, Y. (2017). Pengembangan Handout Berbasis Guided Note Taking untuk Meningkatkan Minat dan Hasil Belajar Fisika Kelas X Sma Negeri 1 Jetis. Jurnal Pendidikan Fisika, 6(4), 283-292.

Sari, A. S., \& Putri, S. N. (2020). Pengembangan Handout Materi Sistem Koloid Berbasis Guided Note Taking untuk Meningkatkan Hasil Belajar dan Respon Siswa Kelas XI SMA. JIPI (Jurnal IPA Dan Pembelajaran IPA), 4(1), 41-59.

Sari, S. A., Jasmidi, Kembaren, A., \& Sudrajat, A. (2018). The Development of Handout Based on Guided Note Taking to Improve the Quality of Analytical Chemistry Learning. PEOPLE: International Journal of Social Sciences, 4(3), 720-734.

Ulya, R., Sari, S. A., \& Ismayani, A. (2016). Pengembangan Handout Berbasis Guided Note Taking pada Materi Koloid Kelas XI MAN Banda Aceh 1 Tahun Pelajaran 2015 / 2016. Jurnal Ilmiah Mahasiswa Pendidikan Kimia, 1(4), 115-124.

Uyun, Q., Holisin, I., \& Kristanti, F. (2017). Pengembangan Media Handout Segitiga Dengan Model Problem Based Instruction. Journal of Mathematics Education, Science and Technology, 2(1), 115-128.

Wulandari, S., Suarsini, E., \& Ibrohim, I. (2016). Pemanfaatan Sumber Belajar Handout Bioteknologi Lingkungan Untuk Meningkatkan Pemahamankonsep Mahasiswa S1 Universitas Negeri Malang. Jurnal Pendidikan - Teori, Penelitian, Dan Pengembangan, 1(5), 881-884. 